\title{
Exploring Confucius's Teaching Mode and the View of Teachers and Students
}

\author{
Shuyan $\mathrm{Yi}^{1, \mathrm{a}}, \mathrm{Na}$ liu ${ }^{1, \mathrm{~b}}, \mathrm{Yao} \mathrm{Xu}^{2, \mathrm{c}}$ \\ ${ }^{1}$ College of Humanities \&Sciences of Northeast Normal University, Changchun 130117, China; \\ ${ }^{2}$ School of Changchun University of Technology, Changchun 130012, China.

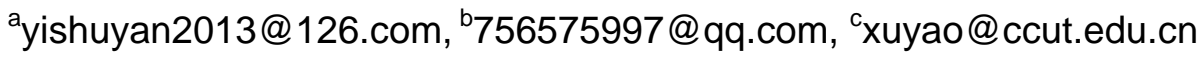

Keywords: Confucius, Teaching mode, Comity, Education.

\begin{abstract}
As the first educator in ancient China, Confucius's theory of related education has important research value. Through combing the contents of the Analects, it can be found that Confucius's teaching mode of harmonious relationship between teachers and students is of great significance to the present. This specific performance in the following aspects: first, focusing on the teaching mode of the question and answer type teaching; second, the Democratic, free and flexible teaching environment; three, the example demonstration function as pay attention to language teaching. Through this teaching mode, Confucius would be a lifetime pursuit of "benevolence" and "ceremony" thought one by one to implement. In the process of teaching, Professor Confucius will give students knowledge about music, and make an example in everyday life to students, to enable students to understand the intrinsic essence of beauty.
\end{abstract}

\section{1 .Introduction}

Now, the Chinese education is at a difficult crossroads, and the educational circles have different views on the future direction which. China's basic education is solid, and the Chinese students often get excellent results in the International Olympic competitions and other international competitions. But, unfortunately Chinese has rarely been a winner of the Nobel Prize and other international awards. This situation has highlighted the weakness and deficiency of the Chinese education in cultivating students' innovative ability. In order to change this phenomenon, Chinese education should be "by the roots", to the ancient educator for enlightenment.

During the Spring and Autumn Period, those intellectuals who have mastered the cultural classics are scattered from the palace to the peoples. ${ }^{[1]}$ Thus, formed the situation of "contention of a hundred schools contention of a hundred schools of though.” In order to promote their academic ideas, the scholars are keen on writing books and lectures. In this context, the "private school" came into being; Confucius opened the first of its kind. This kind of education form has rich teaching content, flexible education system and equal relationship between teachers and students, and it has important enlightenment function to the development of Chinese ancient education thought. This paper mainly point to the view of the relationship between teachers and students of Confucius's educational thinking to sort out. ${ }^{[2]}$

Whether the relationship between teachers and students is harmonious has a decisive impact on the whole educational effect, and he relationship between teachers and students is ultimately controlled by the teacher. ${ }^{[3]}$ In the teaching process, Confucius created a harmonious relationship between teachers and students. Which main have the following characteristics:

\section{2 .The mode of the question and answer type teaching}

According to the records of the Analects of Confucius, Confucius took a relatively open, interactive education approach. He would not force the students to accept his views, while paid attention to let the students speak freely, with the help of dialogue between teachers and students, and discuss the individual's understanding until which is clear. In this regard, Confucius said "bufenbuqi, not 
determined to learn, do not give a corner to corner against three is not complex also." This shows that, in the process of teaching Confucius attaches great importance to the subject position of the students. Confucius said: students and teachers together constitute the teaching behavior, and learning is the key to understanding the individual students, Namely the so-called " Master took the door, practice in each.”

After passing the knowledge to the students, Confucius pays attention to the cultivation of students' subjective spirit through "question", and realize his theory of "learning without thought is useless". Confucius mainly achieved this by two ways:

First, he will ask to the student collective or individual questions, in order to drive students to think independently. His this way of asking questions have a intuitive reflection in the Analects. This paper would take the section of "Zilu, Zengxi, Ranyou, Gong xihua sit by side" in the Analects as an example for analysis.

This section of the text completely records on the "Chi" problem between Confucius and the disciples of the process of questions and answers. After Confucius left the open question to the students, Zilu is the first to do a reply, he advocated the rule of force, and this made his frank, confident character most incisive unfold. Because his answer is not consistent with Confucius's idea of "courtesy", so Confucius did not manage him. While the other disciples follow the ritual act, Confucius gave them the answers one by one after they answered. Zilu, Ranyou, Gongxihua all showed the spirit of active in the world, and they can according to the concept of national governance Confucius's "benevolence" and "ritual". But because of their performance also have a certain gap to Confucius's assertion, so Confucius or "smile", or "sigh", or "cherish" after listened their answers. Only ZengXi showed a longing for a harmonious community, and show the true, good, beautiful vision. Because the expression of Zeng $\mathrm{Xi}$ is Confucius's expected state, so Confucius gave him praise. Through this kind of study way, Confucius not only has a comprehensive understanding to the individual understanding and the individuality of the student's knowledge, and gives a real-time feedback, evaluation. This way of asking questions can drive students to take the initiative to think, so that their knowledge of the learned to be digested and absorbed, and helps to improve the teaching effect.

Second, Confucius encouraged students to take the initiative to ask questions, whether it is not understand or have different views to the knowledge that teacher taught, the students all can ask questions. This situation is more common in the Analects. The main object that the students asked to Confucius main have "benevolence", "gentleman", "political", "friends" and "etiquette" "knowledge" "filial piety" and so on. The following in ask "filial piety" as an example to analysis.

"Filial piety" is a kind of character that Confucius pays great attention to. In the Analects, there are totals of 5 disciples asked Confucius about the question of "filial piety", and they are Meng Yizi, Fan Chi, Meng Wubo, Ziyou, Zixia, etc. This five people on how to practice filial piety heart in reality there are doubts. In response to their problems, Confucius gave five different answers. When Meng Yizi "asked filial piety", Confucius's answer is "no violation", very simple. In this regard, Meng or understand or no doubt, he had no further questions. In this case, Confucius followed the principle of "no understanding no inspiring, not determined to learn", and no further explanation. While the performance of fan Chi is different with Meng Xizi, he did not meet the Confucius's answer, and asked the further question as "what is not illegal?" According to the fan Chi confusion, Confucius did not ignore but for further guidance, and answered as "when they lived, you should be with due respect for your parents; when they died, you should bury them in accordance with the ceremony, and should be in accordance with the ritual worship them." In this part, Confucius made a further explanation of "filial piety" from three different occasions. Through this detailed, specific answer, Fan Chi had a clear cognition to the connotation of "filial piety". In addition, when Meng Wubo asked "filial piety", Confucius made the term of "filial piety" refers to the location of the sons in the performance of his parent's illness; while to the question of Ziyou, Confucius made the term of "filial piety" refers to the respect of the elderly parents; to the question of Zixia, Confucius made the term of "filial piety" refers 
to the speaking kindly to their parents. Through this specific, clear answer, Confucius gave a careful answer to the students' questions and received good teaching results.

In short, in the process of teaching Confucius attaches great importance to "ask", and in order to achieve the "waiting to be asked" teaching mode. ${ }^{[4]}$ Confucius's "educational dialogue" is mainly embodied by the specific context, Can not only encourage students to take the initiative to think, but also can deepen the understanding of knowledge, and eventually to the ability of students to sublimation.

\section{3 .The democratic, free and flexible teaching environment}

Different with today's classroom education, Confucius used the implementation of the lectures, study tour education mode. This kind of education mode is more flexible and free, and it can help to get a good teaching effect.

First of all, in the environment of learning to learn, the students' physical and mental are relaxed, which makes the student's brain is more active, and able to accept the information with high efficiency. In the Analects, the questions and answers between Confucius and his disciples more happened out of the doors. Such as: "The lecture in the side of the altar", "in the country of Chen", "listened Shao in Qi country”, "Under threat in Kuang”, “On the river”, etc. Although this flexible informal teaching environment although no school environment quiet, but it is more vitality, timeliness, change. The different places and natural environment are not only able to open the mind of the students, but also can slow down the rhythm of their knowledge, and give the students more time to comprehend and think. In addition, through direct contact with the real situation, it can provide valuable internship opportunities for students to apply knowledge into reality. This is also beneficial to achieve the efficiency of learning.

Secondly, in the sitting room environment, can achieve close contact between teachers and students.

In the room for educational activities, the distance between Confucius and the students is very close, often in a circle around the way together. The seat arrangement contains equal dialogue spirit between Confucius and his students. In the lecture, Confucius does not require students to sit very norms, learning atmosphere more relaxed freedom, democracy and equality.

The section of "Zilu, Zengxi, Ranyou, Gongxihua sit by side" in the Analects is a good example for this. In this record, Zeng Xi is listening to Confucius and classmates talk, while playing the harp. The melodious music to create a relaxed and pleasant learning atmosphere; and the human spirit is free at this time. This kind of teaching environment, which can make the students speak freely, and can be Confucius' democratic attitude embodied most incisive.

\section{4 .The example demonstration function as pay attention to language teaching}

As the founder of Confucianism, Confucius has a dual identity of the thinker, educator. In order to restore the traditional "ritual" culture and publicity "benevolence" and "courtesy" thought, Confucius started the "private school", To inherit the ancient culture, and carried out his idea of " believe and like the ancient things ", and trying to carry forward the ritual and music culture. In the process of education, Confucius is an elder who has a kind of mercy. Whether it is the pursuit of knowledge, or the "benevolence" and "propriety" of various ideological practices, Confucius insisted to make an example for the students, in order to carry out a full range of influence, influenced on the education of students.

First, Confucius insisted to have an insatiable desire to learn on the knowledge. "Teaching" and "learning" are two complementary behaviors, none is dispensable. In the Analects, the word of "teaching" appears only 7 times, while the word of "learning" appears as many as 64 times. ${ }^{[5]}$ As a result, we can see the importance of "learning". As the teacher, Confucius himself has a strong spirit of learning. In order to increase his knowledge, Confucius insisted on reading ancient books, and often asks other people for advice. In the learning of traditional culture, Confucius insisted on the 
spirit of humility, and put forward the learning point of view as "among any three people walking, I will find something to learn for sure." It is this spirit of knowledge that made Confucius had great success in his studies. Confucius's educational behavior has been widely recognized by society, which have the same result as the modern educational idea of "if the teacher wants to give the student a bowl of water, he should have a bucket of water first." It can be said that Confucius is a very qualified teacher.

Secondly, Confucius insisted on the application of the knowledge learned to daily behavior. Confucius's dual identity determines that it is essentially different from today's professional teachers. His education is to make today's school education and family education become one. In the process of education, Confucius not only guides the students by language, but also focused on the impact of the daily behavior of students to achieve subtle influence. After through the way of learning and asking to make the students learn the traditional cultural knowledge, Confucius also through speech acts of external performance of the "good" and the essence of the heart "beauty" let the students to recognize. From this, he realized the comprehensive teaching to the students from the outside to inside.

\section{5 .Summary}

In short, as the initial stage of China's ancient education, Confucius's education is closely combined with religion and politics ${ }^{[6]}$. It is under the guidance of "music culture" that Confucius upholds the principle of "beauty" principle; he insisted on the "lecture" and "Virtue" in parallel, the pursuit of "moral education" s philosophy of education. In the process of teaching students, Confucius adhere to the concept of "lifelong learning", through the smell, ask, see, read and other different ways to constantly learn from the traditional culture of nutrition, in the knowledge of the reserves as far as possible, to ensure that the teaching process of knowledge transfer "true". In addition, Confucius adhered to the act in accordance with the "benevolence" and "courtesy" of the principle of acting. Under the support of this kind of idea, Confucius practiced his creative education concept, and created the great era of Chinese education.

\section{Acknowledgments}

This paper was funded by the project of Social Science Foundation of Jilin Province, which project numbered 2016BS48.

Yao $\mathrm{Xu}$ is the Corresponding author of this paper.

\section{References}

[1] G.J. Yang, Notes for the Spring and Autumn Period, Zhong Hua Book Company, Beijing, 1990, pp.1197.

[2] G.J. Yang, Translation and annotation for The Analects of Confucius, Zhong Hua Book Company, Beijing, 1980.

[3] S.Q. Wang, Studies on disciples' thinking modes of Confucius based on"Analects of Confucius", Journal of Nanchang College of Education, (2013) No.11, pp.19-21.

[4] J.J. Kong, Discuss on the basic characteristics of Confucius's educational dialogue speech mode, Confucius Studies, (2007) No.7, pp.19-26.

[5] M.J. Shi, The concept of "learning" in Confucius's educational thoughts, Journal of Shandong Administration Institute and Shandong Economic Management Personnel Institute, (2013) No.8, pp.137-139.

[6] K.Y. Dong, A historical study of the history of Chinese ancient education, Journal of Hebei Normal University (Educational Science Edition), (2013) No.5, pp.25-29. 